\title{
COMPOSICIÓN Y DERIVACIÓN EN MAKÁ Y WICHÍ (FAMILIA MATAGUAYA). DE LA SINTAXIS A LA MORFOLOGÍA ${ }^{1}$
}

\author{
DERIVATION AND COMPOSITION ON MAKÁ AND WICHÍ (MATAGUAYA FAMILY). \\ FROM SYNTAX TO MORPHOLOGY
}

\author{
Silvia Spinelli \\ Universidad Nacional de La Pampa, Argentina \\ Temis Tacconi \\ Universidad de Buenos Aires, Argentina \\ temis.tacconi@gmail.com
}

\section{Resumen:}

En este trabajo nos proponemos hacer una comparación entre los diversos procesos de formación de palabras, especialmente derivación y composición, que ocurren tanto en maká como wichí, dos lenguas de la familia mataguaya. Si bien se postula una relación de mayor semejanza o parentesco entre el chorote y el maká, por un lado, y el wichí y el nivaclé, por otro (Tovar 1964), consideramos que existen semejanzas formales y funcionales en los procesos de derivación y composición entre estas dos lenguas que pueden contribuir a indagar en los procesos de gramaticalización ocurridos en ellas.

Para cumplir tal propósito, nos basamos en una perspectiva tipológico-funcional que abarca no solo la descripción estructural de los procesos de formación de palabras en cada una de las lenguas, sino también la comparación interlingüística. La investigación es de tipo descriptivodocumental.

Palabras clave: morfología, formación de palabras, lenguas del Chaco, gramaticalización, familia mataguaya

\begin{abstract}
:
Our aim in this paper is to compare different word formation processes, especially those of derivation and compounding that take place in Maká and Wichí, both languages of the Mataguayan family. Although it has been established that there is a closer relation between Chorote and Maká, on one hand; and Wichi and Nivaclé on the other hand (Tovar 1964a y b), we propose that these two languages have more aspects in common and that this can help to study grammaticalization processes.

To achieve this goal, we use a functional-typological approach that encompasses structural description as well as interlinguistic comparison. The research carried out for this paper is descriptive-documental.
\end{abstract}

Keywords: morphology, word formation, Chaco languages, grammatic.

Recibido: 09 de abril de $2018 \quad$ Aceptado: 30 de octubre de 2018

\footnotetext{
${ }^{1}$ La investigación cuyos resultados se presentan parcialmente aquí fue financiada por el Consejo Nacional de Investigaciones Científicas y Técnicas (CONICET) de Argentina.
} 


\section{Introducción}

En este trabajo abordamos el fenómeno de la formación de palabras en dos lenguas emparentadas: el maká y el wichí, ambas pertenecientes a la familia mataguaya al igual que el chorote y el nivaclé. Si bien se postula una relación de mayor semejanza o parentesco entre el chorote y el maká, por un lado, y el wichí y el nivaclé, por otro (Tovar 1964a y b), consideramos que las semejanzas entre maká y wichí pueden contribuir a indagar en los procesos de gramaticalización ocurridos en ellas. Para profundizar en estas semejanzas

presentamos diversos morfemas formal y funcionalmente semejantes en ambas lenguas y analizamos su comportamiento tanto morfológico (a qué bases se adjunta, qué clase de palabra dan como resultado, etc.) como semántico (qué matices de significado presentan entre ambas lenguas). Describimos y analizamos aquí varios sufijos derivativos (diminutivos, nominalizadores, agentivos, clasificadores de leñosas, frutos y variedad) y diversos compuestos (parte/todo y relacionales) en ambas lenguas. Además, en el caso del morfema locativo -wet, postulamos como hipótesis la existencia de diferentes estadios de un proceso de gramaticalización, dado que en wichí conforma una palabra independiente de la lengua, mientras que en maká se trata de un morfema ligado. Las semejanzas permiten pensar en un origen común de estos morfemas que a lo largo de la historia de cada lengua se han ido especializando y tomando matices particulares. Debido a que en este trabajo intentamos mostrar la cercanía entre wichí y maká, no mostramos todos los morfemas derivativos y compuestos existentes en las lenguas sino solo los que son comunes a ambas lenguas.

Si bien Tovar (1964a, 1964b) especifica que del grupo de las lenguas mataguayas las más estrechamente emparentadas serían wichí y chorote con el 50\% del vocabulario básico compartido; Fabre (2005) también sostiene que hay una estrecha conexión entre maká y nivaclé (más del $43 \%$ de vocabulario compartido). Sin embargo, el mismo autor señala la necesidad de realizar nuevos trabajos comparativos dado que los datos que manejaba Tovar eran escasos. Este trabajo intenta contribuir a la actualización de la comparación entre las lenguas de la familia mataguaya. 


\section{Derivados y compuestos: dos extremos de un fenómeno}

En este trabajo consideraremos dos aspectos de la palabra compleja: por un lado, los relacionados con la derivación, o sea la formación de palabras a partir de la adición de sufijos a una raíz; y, por el otro lado, aquellos que refieren a la composición, es decir, la constitución de una palabra a partir de la unión de dos o más lexemas.

La derivación es definida aquí como el mecanismo por el cual se forman nuevos lexemas a partir de la unión de un lexema base y un afijo derivativo. Las características más importantes de los afijos derivativos es que no son obligatorios (en contraposición a los afijos flexivos que son requeridos por la sintaxis), compiten con otros afijos derivativos con la misma función, es decir que en una lengua pueden existir distintos afijos que permitan formar nombres de instrumento, por ejemplo; $y$, finalmente, que pueden cambiar la categoría del lexema base (de verbo a nombre, de nombre a adjetivo, etc.). De acuerdo con Bybee (1985), las operaciones derivativas tienden a ser más relevantes para la situación expresada en la raíz que las operaciones flexivas dado que no actualizan al lexema para aparecer en un contexto determinado, sino que crean nuevos significados. Por su parte, Haspelmath (2002: 68) asegura que los significados derivativos son más diversos que los de las categorías flexivas. Así, además de significados más extendidos en las lenguas del mundo, como agente, instrumento, abstracto, etc., en la comparación lingüística, también encontramos significados específicos que se reducen a algunas lenguas, como planta leñosa o valor despectivo.

Por su parte, consideramos la composición como la unión o combinación de dos o más formas libres para constituir una forma compleja que, desde el punto de vista conceptual, fónico y funcional, representa una unidad léxica. Sintácticamente, los compuestos se comportan como una palabra simple, con la distinción de que tienen una estructura interna. Es por esto que en algunos casos el significado del compuesto es transparente y composicional, donde ambos lexemas conservan su significado original que puede deducirse de la suma del significado de sus elementos constituyentes; mientras que en otros, es opaco. En el análisis de los compuestos de las lenguas bajo estudio nos interesa su estructura interna y las relaciones semánticas que se establecen entre los lexemas que los constituyen. En cuanto a la estructura interna, analizamos aquí la categoría léxica de sus elementos constituyentes y la relación entre ellos. Estas relaciones, a su vez, reflejan, en la 
mayoría de los casos, otras relaciones estructurales de la lengua (orden de constituyentes, alineamiento de persona, tipo de marcación en el núcleo o en el dependiente). En cuanto al aspecto semántico, en términos tipológicos se sostiene que entre los elementos de un compuesto pueden establecerse relaciones atributivas, genitivas, descripción de un propósito o genérico-específico (Aikhenvald 2007: 30-31).

Finalmente, nos centramos en un posible fenómeno de gramaticalización, definido por Hopper y Traugott como el proceso por el cual lexemas y construcciones sintácticas pasan a tener funciones gramaticales y una vez gramaticalizadas continúan desarrollando nuevas funciones en determinados contextos (1993: xv). La comparación entre lenguas emparentadas como el maká y el wichí permiten ver este tipo de fenómenos en diferentes estadios.

\section{Aspectos generales de maká y wichí}

Como señalamos en la introducción, ambas lenguas pertenecen a la familia mataguaya, junto con el chorote y el nivaclé, y se hablan en la región del Gran Chaco. El wichí se extiende en el norte de Argentina: este de la provincia de Salta, oeste de Formosa, y noroeste de Chaco; y también en una pequeña zona en el sur de Bolivia. Aunque no se conoce con exactitud la cantidad de personas que conforman la etnia, las fuentes existentes hablan de 35.000 a 60.000 en Argentina y 2.000 en Bolivia, la mayoría de ellos hablantes de la lengua (cfr. Censabella 1999: 79-80; Claesson 1994: 1). Según el censo del 2010 (INDEC), 50.419 personas se reconocen como pertenecientes a la etnia wichí (en Argentina). Es considerada una de las lenguas indígenas más vitales de la Argentina.

Para este trabajo nos basamos en un corpus registrado en sucesivos trabajos de campo llevados a cabo desde el año 2005, en varias comunidades wichí de la provincia de Salta, en la región del río Pilcomayo: Misión Santa María, Misión San Luis y Cañaveral (Santa Victoria Este).

El maká, por su parte, es hablada por alrededor de 2000 personas en Paraguay. Actualmente, el grupo más numeroso de la población habita en el distrito Mariano Roque Alonso. Existen, sin embargo, otros dos asentamientos: Qemkuket, ubicado en la localidad José Falcón (departamento Presidente Hayes, a 48 kilómetros de Asunción), e Ita Paso, 
situado en la localidad homónima (departamento Itapúa, a 365 kilómetros de la capital). ${ }^{2}$ Los tres grupos tienen una conexión estrecha y responden al mismo líder. A pesar de ser un grupo relativamente reducido de hablantes, se caracterizan por poseer una fuerte valoración de su lengua. La mayor parte de las mujeres y los niños en edad preescolar son monolingües en maká.

Desde el punto de vista tipológico, tanto el maká como el wichí son lenguas aglutinantes con tendencia a la polisíntesis, con marcación en el núcleo. Ambas coinciden en que el orden básico de los constituyentes en la oración es SVO para las transitivas y VS para las intransitivas. Los procesos de formación de palabras en la lengua maká involucran la derivación por sufijación y diferentes tipos de compuestos. La lengua ha sido estudiada desde principios del siglo XX por Belaieff (1931, 1940) y Schmidt (1937). El primer estudio gramatical completo y el primer diccionario fueron el resultado de la investigación de Gerzenstein (1995, 1999, respectivamente, entre otros). Los aspectos fonológicos y morfosintácticos básicos de la lengua maká han sido previamente analizados y estudiados (Gerzenstein1989, 1991, 2001, 2002; Messineo2009, 2011, 2015; Messineo, Carol y Klein 2016; Tacconi 2013, 2015). Los procesos de formación de palabras han constituido el foco de otros trabajos (Tacconi 2014, 2015, 2016b; Tacconi y Abrach 2015; Messineo y Tacconi 2010).

Con respecto a la lengua wichí, los estudios previos datan desde fines del s. XIX hasta la década del ' 40 partir de distintas publicaciones realizadas por misioneros ingleses. Desde 1974 contamos con descripciones (completas o de algún nivel de la lengua) realizadas por lingüistas en distintas variedades: Viñas Urquiza (1974), en la variedad de Embarcación, Salta; Braunstein y Messineo (1990), en Formosa; Gerzenstein (1992, 2002) compara distintas variedades de las provincias de Salta, Formosa y del sur de Bolivia; Claesson (1994), en el sur de Bolivia; Terraza (2009), en Rivadavia Banda sur, provincia de Salta; Nercesián (2012) y Cayré-Baito (2013), en Formosa y Spinelli(2015) en Salta.

El único trabajo comparativo entre la lengua wichí y maká se refiere a la fonología y pertenece a Gerzenstein (2002), quien, en su artículo "Las consonantes laterales y las labializadas en lenguas mataguayas del Chaco Argentino-Paraguayo" revisa dos

\footnotetext{
${ }^{2}$ Según el censo de DGEEC (2004), el 77,4\% de la población maká vive en un área urbana, mientras que sólo el $22,6 \%$ restante habita en espacios rurales.
} 
consonantes documentadas en los inventarios fonológicos de casi todas las lenguas mataguayas del Chaco: la lateral fricativa y la fricativa labializada, que se caracterizan por la inestabilidad de sus componentes y por la similitud que manifiestan en su comportamiento fonético-fonológico. El objetivo de la lingüista es mostrar la correspondencia regular que se observó entre estos dos fonemas y los respectivos del maká. Las lenguas mataguayas analizadas son el chorote (variedad 1 y 2), wichí (abajeño y arribeño), mataco salteño u occidental y maká.

Se registran trabajos comparativos de todas las lenguas de la familia como lo publicados por Fabre (2005) y entre lenguas mataguayas y guaycurúes (Viegas Barros 1993), entre otros.

En cuanto a los procesos que nos atañen en este trabajo, para estudiarlos en ambas lenguas, además del análisis de textos recopilados y de datos de segunda mano (diccionarios, gramáticas, etc.), hemos necesitado recurrir a la elicitación, ya que la ocurrencia espontánea de determinados lexemas derivados es poco frecuente, por ende nos resultaba complejo hallarlos en los textos. Por la misma razón, los lexemas derivados que registramos en el corpus de textos fueron sometidos a varias pruebas con los consultantes más avezados.

\section{Derivación y composición en maká (MK) y wichí (WI)}

En primer lugar, abordamos el fenómeno de la derivación. En ambas lenguas éste se produce por sufijación. Tanto en maká como en wichí, encontramos los siguientes sufijos derivativos: instrumentales/agentivos; locativos; de nombres abstractos, $\mathrm{y}$, considerando el léxico etnobiológico, los evaluativos, los marcadores de clase 'plantas leñosas' y marcador de clase 'fruto'.

\subsection{Derivación}

\subsubsection{Instrumentales/Agentivos}

\section{Sufijo -wo' (MK)/-wo (WI)}

En maká, el sufijo -wo’ permite derivar nombres de instrumento a partir de verbos. En estos casos, el lexema resultante designa un elemento que se utiliza para realizar la acción a la que remite el verbo base. Por ejemplo en (1) el lexema derivado se forma a 
partir del verbo de -atsxan 'rallar' para designar al instrumento utilizado para rallar las raíces de la mandioca brava. ${ }^{3}$

MK

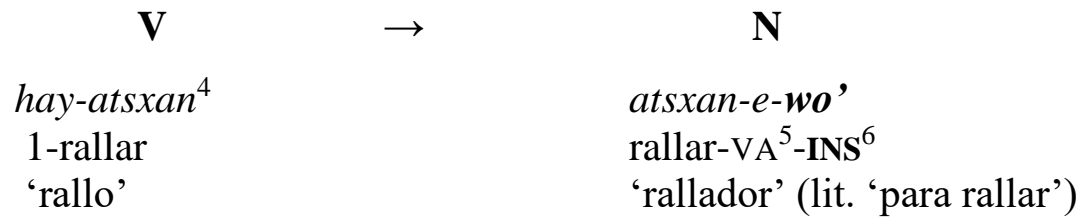

Este morfema se sufija también a bases nominales. El lexema resultante, desde el punto de vista semántico, denomina un instrumento u objeto con una finalidad precisa. En este caso, las bases nominales designan el objeto para el cual sirven o al que se aplican los instrumentos denotados por los lexemas derivados (en cambio, los sustantivos instrumentales derivados de verbos toman como base una acción o actividad). A continuación, consignamos algunos ejemplos con este sufijo:

MK

wit-yaqsi'

POSS.INDF-dedo de la mano 'dedo de la mano'

\section{$\mathbf{N}$}

yi-to-wo-ts

POSS1-ojo-INS-PL 'anteojos' (lit. 'para mi ojo')

wit-yaqsi-wo-ts

POSS.INDF-dedo-INS-PL 'guantes' (lit. 'para los dedos')

${ }^{3}$ Este instrumento es un leño sobre el que se coloca una chapa con agujeros que actúan como dientes (Gerzentein 1999 135).

${ }^{4}$ Por pedido expreso del pueblo maká utilizamos en la transcripción el alfabeto estandarizado. A continuación consignamos las equivalencias con el alfabeto fonético: a /a/, e /e/, f/f/, h/h/, i /i/, j/x/, k/k/, l/1/, m/m/, n/n/, $\mathrm{o} / \mathrm{o} / \mathrm{p} / \mathrm{p} /, \mathrm{q} / \mathrm{q} /, \mathrm{s} / \mathrm{s} /, \mathrm{t} / \mathrm{t} /, \mathrm{ts} / \mathrm{s} /, \mathrm{u} / \mathrm{u} /, \mathrm{w} / \mathrm{w} /, \mathrm{y} / \mathrm{y} /, \mathrm{t} / \mathrm{t} /, \mathrm{x} / \chi /,{ }^{\prime} / \mathrm{r} /$.

${ }^{5}$ Cuando los sufijos que comienzan con un fonema consonántico se adjuntan a una raíz que termina en consonante puede aparecer una vocal de apoyo o epentética /i/ o /u/ o una vocal precedida por una fricativa laríngea /h/ (Gerzenstein 1995). En ambos casos la glosamos como vocal de apoyo (VA).

${ }^{6}$ Abreviaturas utilizadas tanto para el maká como para el wichí son: 1, 2, 3: primera, segunda y tercera persona; 3.INDEF: tercera persona indefinida; APL: aplicativo; ADV: adverbio; AG: agente; AUM: aumentativo; CAU: causativo; CL: clasificador; CLEV: clasificador evaluativo; CLFR: clasificador fruto; CLLÑ: clasificador leñosa; CERT: certitivo; CON: conector; DEM: demostrativo; DESP: despectivo; DIM: diminutivo; DIR: direccional; DUR: durativo; F: femenino; FREC: frecuentativo; FUT: futuro; COORD: coordinante; IM: imperfectivo; INST: instrumental; INDF: indefinido; NEG: negación; NMLZ: nominalizador; LOC: locativo; OB: objeto; PDO.: pasado; PL: plural; POSS: posesivo; REC: recíproco; REF: reflejo; SUB: subordinante; SUJ: Sujeto; VA: vocal de apoyo.

${ }^{7}$ La oclusión laríngea de final de palabra cae cuando se adjunta un sufijo. 

carro
carro-VA-INS
'carro'
'buey' (lit. 'para el carro')

No obstante, en algunos ejemplos documentados, la relación semántica es menos

directa:
wit-jus
wit-jus-i-wo'
POSINDEF-cara
POSSINDF-cara-VA-INS
'cara'
'hebilla' (lit. 'para la cara')

En wichí encontramos el mismo sufijo -wo con el valor de agente. Puede derivar sustantivos a partir de una base verbal activa. Es altamente productivo, ya que participa en la formación de sustantivos que refieren a ocupaciones o profesiones y cuyos referentes son siempre animados.

(6)

$\mathbf{N}$
$h u p^{8}$
casa
'casa'

(7)

$$
\begin{aligned}
& \text { papel } \\
& \text { papel } \\
& \text { 'papel' }
\end{aligned}
$$

$$
\begin{aligned}
& \text { qača } \\
& \text { remedio } \\
& \text { 'remedio' }
\end{aligned}
$$

$\mathbf{N}$

hup-wo
casa-AG
'albañil' (lit. 'el que hace la casa')

papel-wo

papel-AG

'maestro' (lit. 'el que hace papel')

$q a \check{a} a-w o$

medicina-AG

'médico' (lit. 'el que hace

Medicinas')

También pueden formarse sobre bases verbales que suelen nominalizarse por medio de los nominalizadores ${ }^{9}$-yah o $-\boldsymbol{e q}$, para que puedan recibir el sufijo agentivo:

\footnotetext{
${ }^{8}$ Los fonemas de la lengua wichí (variedad del Pilcomayo) son: /m, n, p, p', t, c, č, č', k, k', kw, $, h^{\mathrm{w}}, \mathrm{s}, \mathrm{l}$, h, l, w, y, a, $\Lambda, \mathrm{e}, \mathrm{i}, \mathrm{o}, \mathrm{u} /$

${ }^{9}$ En la lengua wichí, variedad del Pilcomayo, hemos registrado tres tipos de nominalizadores a los que denominamos 'Nominalizador 1'(abstractos: -ah/yah), 'Nominalizador 2' (oficio: -cah) y 'Nominalizador 3' (concretizador: -eq) (Spinelli, 2015).
} 
WI

$\mathbf{V}$
$o-$ čuh$^{w} a n$
1-enseñar
'enseño'
o-lesay
1-escribir
'escribo'

$\mathbf{N}$

-čuhwan-yah-wo enseñar-NMLZ1-AG

'maestro'

-lesayn-eq-wo

escribir-NMLZ3-AG

'escritor'

Con respecto al ámbito de la fauna, este sufijo deriva sustantivos denominales que indican la actividad típica que realiza el animal, como se observa en los ejemplos (11) y (12).

WI

cawotah

miel

'miel'

(12)

hohnat

tierra

'tierra'
$\mathbf{N}$

cawotah-wo

miel-AG

'abeja' (lit. 'el que hace la miel')

hohnat-wo

tierra-AG

'lombriz' (lit. 'el que hace la tierra')

Si bien los lexemas resultantes en ambas lenguas no pertenecen al mismo tipo (instrumental vs. agentivo), es un fenómeno tipológicamente frecuente que instrumentales y agentivos (y también comitativos) tengan una misma forma o deriven uno de otro, dado que pueden considerarse semánticamente relacionados. En Heine y Kuteva (2002: 80) se señala que el camino más frecuente de gramaticalización es comitativo> instrumental > agente/ergativo. Esto nos permitiría pensar que la lengua wichí tiene un grado mayor de gramaticalización dado que en esta lengua el sufijo -wo tiene un valor agentivo, último en la ruta de gramaticalización.

\subsubsection{Locativos/Recipiente}

\section{Sufijo -jii (MK)/-hi (WI)}

Estos sufijos, parcialmente homófonos en ambas lenguas, se utilizan para construir lexemas que denotan locativo, específicamente recipiente. En la mayoría de los casos, estos 
sufijos se añaden a un sustantivo y forman un lexema que señala el recipiente que contiene al referente del lexema base. Como observamos en los ejemplos siguientes:

$$
\begin{aligned}
& \text { finka } \\
& \text { tabaco } \\
& \text { 'tabaco' }
\end{aligned}
$$

aqfinet

pisón

'pisón'

(15) $\mathrm{fet}$

fuego

'fuego'

(16) uti

orina

'orina'
$\mathbf{N}$

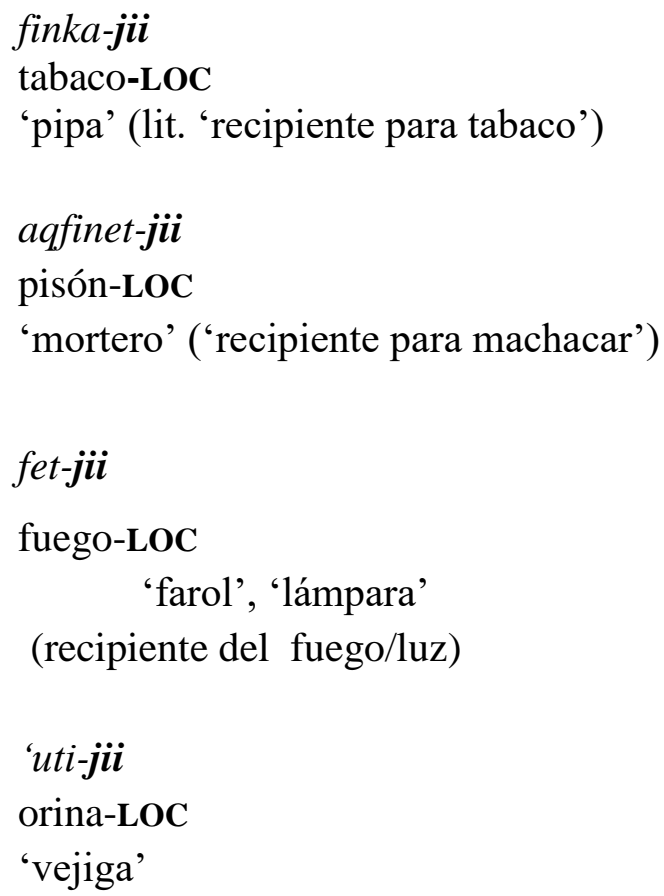

En maká, este sufijo tiene un matiz locativo general que indica 'lugar dentro de o en el interior de', en estos casos se adjunta a bases verbales y se utiliza para denominar el lugar donde se desarrolla la acción denotada por la raíz verbal. Por ejemplo, en (17) se observa la derivación de -inpujitjii 'baño' a partir del verbo -inpujin 'bañar a alguien'. Por un proceso de transferencia semántica el vocablo también se utiliza para designar a la piscina.
MK V
$\rightarrow \quad \mathbf{N}$
(17) -inpujin
wit-inpuji-t-jii
-bañar
POSSINDF-bañar-CAUS-LOC
'bañar a alguien'
'el baño/la piscina' 
En wichí se trata del sufijo -hique posee el valor de 'recipiente'. Este morfema se aplica a ciertos sustantivos para señalar la idea de 'recipiente' o 'lugar cerrado' y da por resultado otro sustantivo. Es un sufijo bastante productivo en esta lengua.

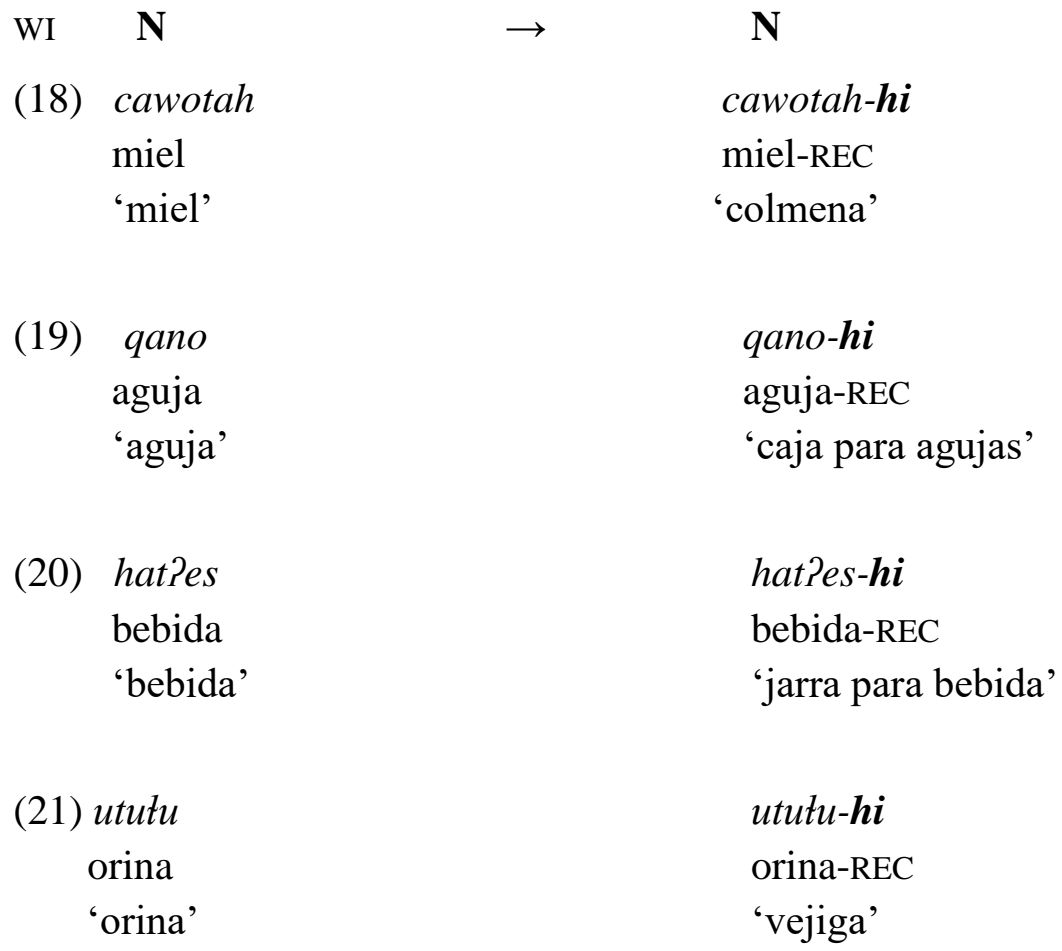

Obsérvese que estos sufijos son parcialmente homófonos en ambas lenguas y que, en casos como (16) (21) conforman lexemas sinónimos a partir de raíces nominales también sinónimas ( 'uti-jii -ututu-hi 'vejiga').

Cabe resaltar que en otras lenguas de la región chaqueña también existen sufijos equivalentes. En toba se trata de /-ki/ (Messineo 2003: 105); en pilagá, en cambio, el mismo marcador tiene el sentido de 'objeto manufacturado por el hombre' (Vidal 1997: 64).

Obsérvese asimismo que la relación entre locativo y recipiente es similar a la encontrada entre agente e instrumento, es decir que son cercanas en términos semánticos.

\subsection{Nombres Abstractos}

\section{Sufijos -(y)ax/-(y)ex(MK)/-ah/-yah (WI)}

Los sufijos -(y)ax/-(y)ex, en maká, son utilizados para obtener sustantivos abstractos a partir de verbos. Cuando la base verbal termina en $-y$, se selecciona -ax/-ex. 
MK

$\mathbf{V}$
-ijiwey
-tener.miedo
'tener miedo'

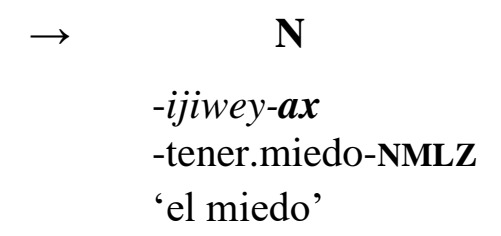

-ijiwey-ax

'el miedo'

De manera equivalente, en wichí, el sufijo -yah, muy productivo, deriva sustantivos 'abstractos'. Opera sobre bases verbales, generando sustantivos. Viñas Urquiza (1974) y Terraza (2009) también lo registraron en sus datos en otras variedades del wichí. Podemos advertir que este sufijo produce cambios de tipo morfofonológicos en el lexema derivado. Según nuestros registros, son pocas las bases que permanecen intactas tras la incorporación del sufijo derivativo, por ejemplo:

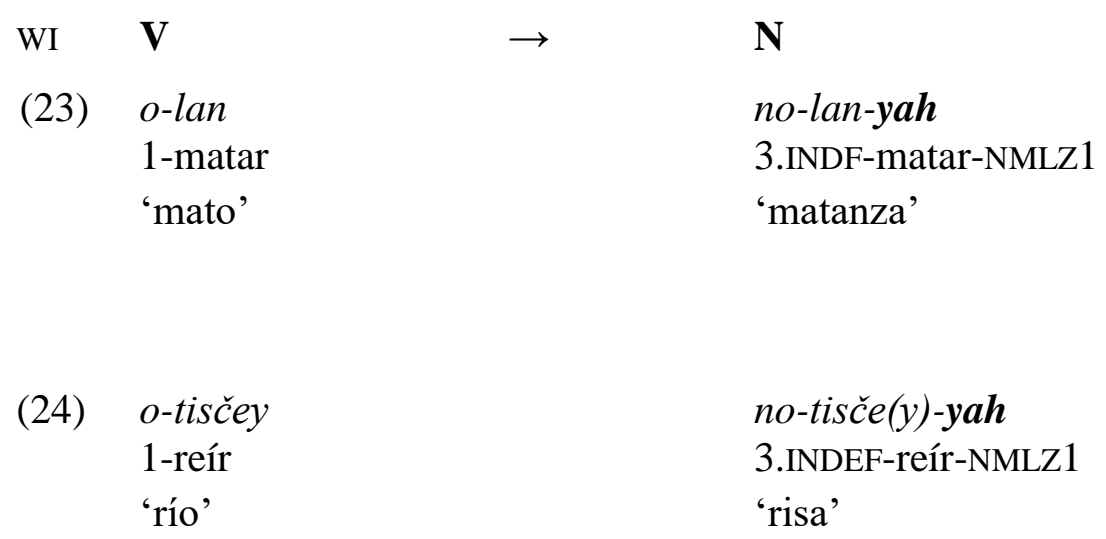

En otros casos, las bases presentan ciertas modificaciones, por ejemplo, como vemos en (25), el sufijo durativo - $t i$ obligatoriamente se adjunta a la base verbal. No obstante, una base nominalizada no es compatible con el morfema de aspecto verbal:

$\begin{array}{lcc}o-\check{c} u m-t i \rightarrow & \text { no- } \check{c} u m-\boldsymbol{a h} & * \boldsymbol{n o - c ̌ u m - t i - a h} \\ \text { 1-trabajar-DUR } & \text { 3.INDF-trabajar-NMLZ1 } & \text { 3.INDF-trabajar-DUR-NMLZ1 } \\ \text { 'yo trabajo' } & \text { 'trabajo' }\end{array}$

\subsubsection{Léxico etnobiológico}

Sufijo evaluativo: -tax (MK)/-tah-tas(WI)

Altamente productivo, -tax funciona en maká como un clasificador de variedad que deriva sustantivos que refieren a plantas y animales a partir de otros ya existentes en los 
mismos dominios. Los sustantivos derivados mediante este sufijo categorizan variedades zoológicas y botánicas percibidas como ‘anómalas' (26) o 'no autóctonas' (27) en relación con la variedad más conocida o prototípica.

MK

etsxitiyi

'sandía'

Citrulluslanatus $\left(\mathrm{AG}^{10} 164\right)$
$\mathbf{N}$

etsxitiyi-tax sandía-CLEV 'melón' (lit.: 'sandía anómala') Cucumismelo (AG 164)
(27) etuyaj

caraguatá.textil

'caraguatá textil'

Deinacanthonurbanianum etuyaj-tax

caraguatá.textil-CLEV

'variedad de caraguatá (ausente en el Chaco)'

Pseudananassagenarius (AG 147)

En la formación de sustantivos referidos a animales, -tax también categoriza variedades semejantes pero más llamativas, domésticas, o de diferente color o de mayor tamaño (28):

MK

ehe'

loro

'loro'

Amazona aestiva (AG 142) ehe'-tax

loro-CLEV

'papagayo' (lit.: 'loro grande o más llamativo')

Ara sp. (AG 142)

Como establecen Messineo y Cúneo (2010), este sufijo posee un matiz evaluativo que lo pone en conexión con la noción de aumentativo. La misma forma la registramos en wichí como un sufijo derivativo de aumentativo (30 a 33). En el caso del wichí, este sufijo no es exclusivo de la flora y fauna, como muestra el ejemplo (29), pero ha sido registrado

\footnotetext{
${ }^{10}$ Utilizamos las siguientes abreviaturas para señalar las fuentes empleadas para la identificación de la fitonimia y la zoonimia maká: AG: Gerzenstein 1999; JB: Braunstein 1981 y PA: Arenas 1983.
} 
también dentro de este campo semántico por Suárez ${ }^{11}$ (2010: 207) en nombres de plantas semejantes pero de distinto tamaño y también en nombres de animales para indicar variedad.

Aquí tenemos una base sustantiva seguida por un morfema derivativo que significa 'aumentativo'. El resultado es otro sustantivo.

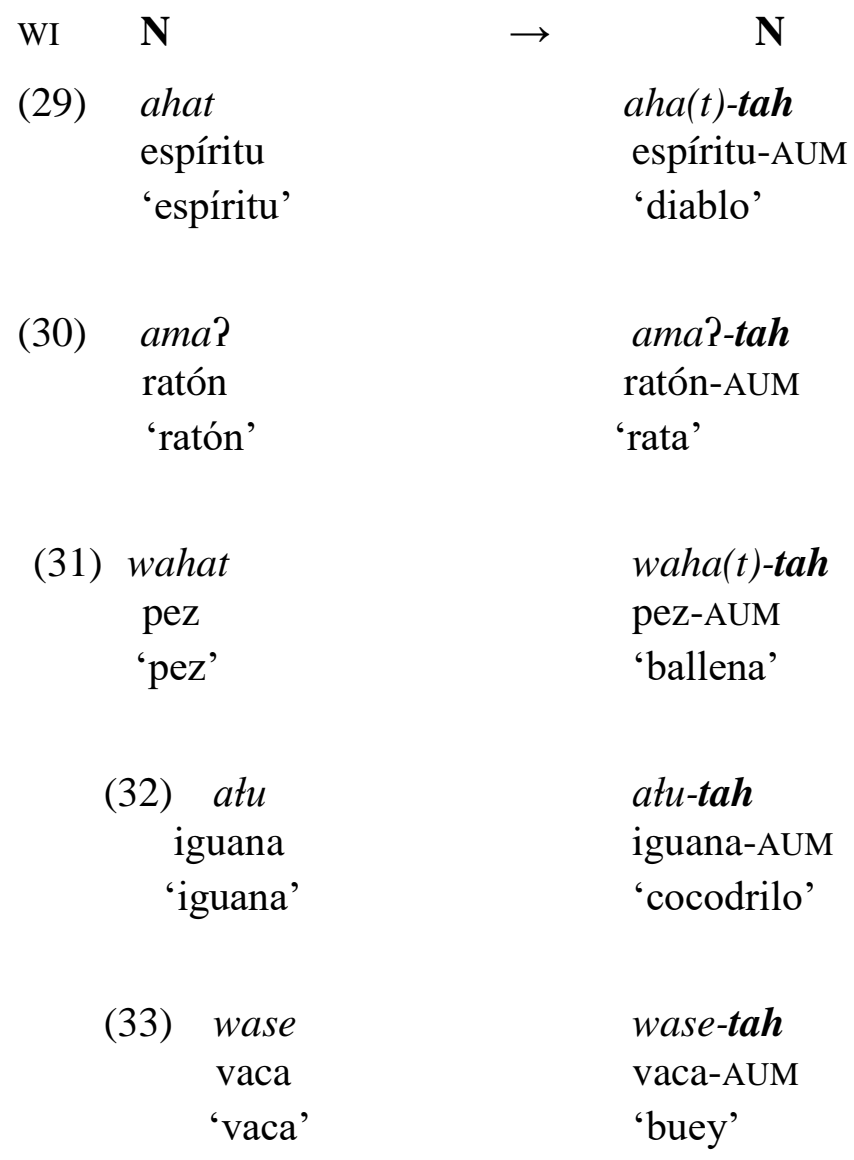

Por otra parte, como se puede observar en los ejemplos a continuación, el valor evaluativo de los cognados -taj (MK) y -tas (WI) parece extender su valor en wichí. En esta lengua, el sufijo se añade a bases de diversas categorías (sustantivos, verbos y pronombres indefinidos) y agrega, sin cambiar la categoría de la base, valor despectivo.

\footnotetext{
${ }^{11}$ La autora trabajó con las comunidades wichí asentadas en la provincia de Salta, específicamente en Morillo y Los Baldes.
} 
WI

$$
\mathbf{N}>\mathbf{N}
$$

(34) ;a-qais-tas $\varnothing$-t’uqe-am!

2-novio-DESP 3-buscar-2

'¡tu novio te busca!'

\section{Indef $>$ Indef}

(35) ihnyah-tas $\emptyset$-hape bilinweswet $\emptyset$-wawutita-s ta manse-s otros-DESP3-ser bilingüesy 3-ser igual-PL SUB chico-PL

'otros 'esos' son bilingües, son iguales que los chicos' ${ }^{12}$

$\mathbf{V}>\mathbf{V}$
(36) o-hane-tas t'at o-atyhi
1-usar-DESP CERT 1-idioma
'usan nuestro idioma'13

Los valores semánticos de anómalo, despectivo o extraño parecen ser parte de la misma esfera semántica que el aumentativo. Esta transferencia de valores entre aumentativo y despectivo se registra también en otras lenguas, como refiere Cúneo (2015: 631) para el toba donde el sufijo aumentativo -naq(M)/-naGa(F) puede utilizarse también para denotar significados peyorativos, burlas o insultos.

\subsubsection{Sufijos derivativos del dominio semántico flora}

Un grupo de sufijos, específico del dominio semántico de la flora, está integrado por morfemas derivativos que codifican 'especies leñosas', 'pluralidad de vegetales', 'fruto' y 'comunidad vegetal' y son, en este sentido, claramente marcadores morfológicos de clase. A diferencia de -tax estos son morfemas obligatorios para raíces específicas, poseen un significado homogéneo y forman un número reducido de clases.

\subsubsection{Marcador de clase 'plantas leñosas': -Vk(MK) y -uq(WI)}

La mayoría de los sustantivos que designan plantas leñosas (árboles, arbustos, lianas y ciertas enredaderas) ${ }^{14}$ reciben en maká el sufijo $-\mathrm{V} k$, siendo /u/ y /e/ las vocales más frecuentes que preceden a la consonante $/-k /$ :

\footnotetext{
${ }^{12}$ En esta secuencia, el mismo consultante continúa su relato y comenta en forma irónica que según los maestros criollos, los auxiliares bilingües son iguales que los chicos (en cuanto a actitudes y comportamientos).

13 Aquí el consultante hace referencia a los maestros criollos que usan el idioma wichí en tono burlesco.
} 
MK

(37) ininq-ak

algarrobo.blanco-CLL $\mathbf{L} \tilde{\mathbf{N}}$

‘algarrobo blanco' (Prosopis alba)

(38) asept-uk

cina-cina-CLL̃̃

'cina-cina o retamo rojo' (Parkisoniaaculeata)

fil-ek

duraznillo-CLL̃

'duraznillo' (Ruprechtia triflora)

(40) fonfon-ok

naranja.de.monte-CLL $\mathbf{L}_{\mathbf{N}}$

'naranja de monte o payaguá naranja' (Capparisspeciosa)

Formalmente similares, los sufijos - $V k$ del chorote (cfr. Scarpa 2006) e -ik del toba (Messineo y Cúneo 2010) se aplican también a sustantivos que designan plantas leñosas.

Por su parte, en la lengua wichí hemos detectado un marcador de clase 'leñosas'15, $u q$, que deriva el sustantivo que denomina al árbol a partir del fruto. En wichí, la mayoría de los sustantivos que designan plantas leñosas presentan este sufijo.

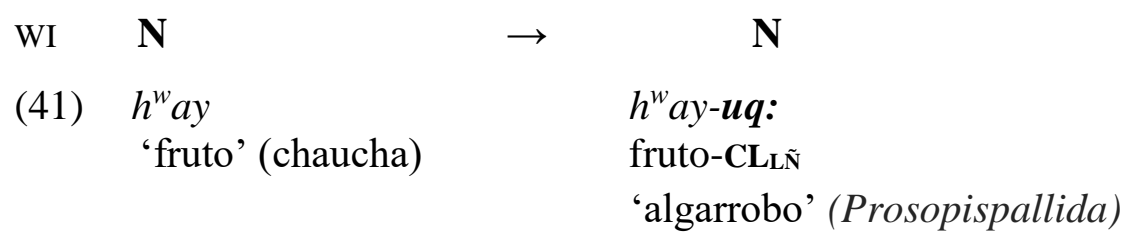

\footnotetext{
14 "Las plantas leñosas son aquellas plantas vasculares que presentan tallos perennes, que se encuentran por encima de la superficie del suelo y están cubiertos de una capa de espesa corteza. La flora leñosa comprende generalmente árboles, arbustos, lianas, ciertas palmeras, enredaderas y cactus (arborecentes) (Scarpa 2006; Suárez 2010: 211; Rosso 2010)" (Cúneo 2013: 220).

${ }^{15}$ Este marcador también fue encontrado en varias lenguas emparentadas y vecinas: por ejemplo, en la lengua toba, se trata del sufijo -ik (Messineo y Cúneo 2010); en chorote (Scarpa 2006) y maká (Gerzenstein 1994), el sufijo $-\mathrm{V} k$, siendo /u/ y /e/ las vocales más frecuentes que preceden a la consonante /-k/. No obstante, en otras variedades del wichí, no han sido registrados clasificadores nominales como los mencionados.

Según Suárez (2010: 211), los sufijos -ekw y -aq son identificadores de plantas leñosas: árboles, arbustos, cactus arborescentes y arbustivos, palmeras arbóreas y hasta arbustos hemiparásitos llevan este sufijo. Solo las plantas subarbustivas no lo poseen en ningún caso.”
} 
Otros casos de los que no encontramos el morfema base son:

(42) sičuy-uq

?-CLLN

'sauce' (Salix)

\section{lečen-uq}

?-CLL̃̃

'chañar' (Geoffroeadecorticans)

\subsubsection{Marcadores de clase 'fruto': $-\boldsymbol{i}$, $-\operatorname{axy}-\boldsymbol{a}$ ' (MK); $-\boldsymbol{y}$ (WI).}

En maká, en el dominio semántico de las plantas, la diferencia entre árboles y frutos se indica también mediante un proceso de derivación. Los morfemas que especifican 'fruto' son sufijos que se añaden a las raíces que refieren a especies vegetales. El maká presenta en algunos sustantivos de frutos los siguientes sufijos: $\boldsymbol{- i}, \boldsymbol{a} \boldsymbol{a x} \mathbf{y}-\boldsymbol{a}$ ':

MK

lekit-uk zapallo- $\mathbf{C L}_{\mathbf{L} \tilde{\mathbf{N}}}$

'zapallo'

athey-uk

molle.negro-CLL̃

'molle negro' lekit-i

zapallo-CLFR

'fruto del zapallo'

athey-ax

molle.negro-CLFR

'fruto del molle negro'

fitskuteyk-a' coco mboyaca-CLFR 'fruto del coco'

En wichí, del mismo modo, los morfemas que distinguen 'fruto' también son sufijos que se añaden a las raíces que aluden a especies vegetales. Aunque cabe resaltar que la mayoría de los sustantivos de frutos se forman por la composición ha?la + lay 'fruto del árbol' (lit. 'árbol su fruto'). 
'fruta de algarrobo'

wosu-y algarrobo-CLFR

'fruta de algarrobo negro'

(49) $q e(t)-a y$

cedro-CLFR

'fruta de cedro'

\subsection{Compuestos}

Existen diversos tipos de compuestos en las dos lenguas. En este trabajo, clasificamos los compuestos de acuerdo con la relación semántica entre los elementos que los componen y describimos su estructura morfosintáctica. Si bien las relaciones halladas entre los elementos de estos compuestos no son exclusivas de estas lenguas, sino que son tipológicamente frecuentes, consideramos relevante para una comparación interlingüística que ambas lenguas utilicen compuestos similares, ya que esto mostraría que siguen patrones tipológicos similares o cercanos. En primer lugar describimos los compuestos parte/todo y, en segundo lugar, los compuestos relacionales con sustantivos como 'hijo' o 'habitante'

\subsubsection{Compuestos parte/todo}

La meronimia es un tipo de relación semántica entre las partes de una cosa y el todo que las incluye (Klein 2000 83). Los dos sustantivos de un compuesto pueden mantener una relación semántica de todo-parte, especialmente cuando expresan posesión, como ha sido señalado por Klein (2000) para distintas lenguas de Sudamérica, principalmente para las chaqueñas. En estas estructuras, el poseído es la parte, mientras que el poseedor es el todo.

En maká encontramos compuestos nominales del tipo Nombre + Nombre que reproducen este tipo de relación parte-todo. De acuerdo con el orden básico de los compuestos en esta lengua, el sustantivo que indica la parte se ubica siempre a la derecha llevando la marca de posesión mientras que el de la izquierda señala el todo (todo-parte). Los compuestos así formados funcionan como metáforas que ponen de manifiesto la relación de semejanza entre la parte del cuerpo de un animal y la planta denotada por el 
compuesto. El significado de la construcción nominal completa es independiente del significado de sus partes:

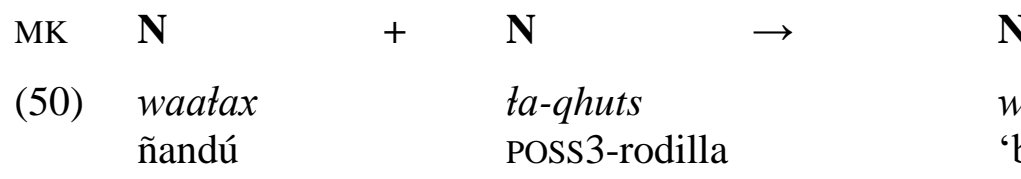

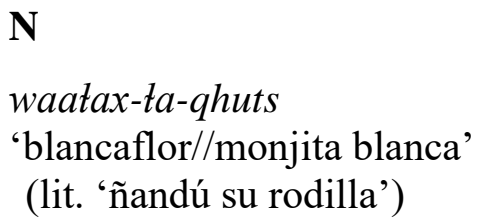

howhowteqetei

'variedad de planta'

(lit.'howhow sus testículos')

(PA 153)

wowotahatsjil

'Cola de zorro' (var. de planta)

(lit. 'zorro sus colas') (PA 187)

jaya-te-su'

'variedad de hongo'

(lit. 'murciélago su vagina')

(PA 156)

melel-t-enjeyits

'variedad de cáctus'

(lit. 'ciervo sus mocos') (PA 153)

En el caso del wichí, encontramos la estructura sustantivo más sustantivo que forma

un verbo descriptivo:

$\begin{array}{llll}\text { WI } & \mathbf{N} & \mathbf{N} \rightarrow & \text { Verbos Descriptivos } \\ \text { (55) } \begin{array}{l}\text { mawo } \\ \text { 'zorro' }\end{array} & & \begin{array}{c}\text { taneq } \\ \text { 'hígado' }\end{array} & \begin{array}{c}\text { mawotaneq } \\ \text { 'ser marrón' } \\ \text { (lit .'zorro su hígado') }\end{array} \\ & & \text { tawo } & \\ \text { (56) hoqtaq } & \text { 'flor' } & \text { hoqtaqtawo } \\ & & & \text { 'ser rosa' (lit. 'flor del } \\ & & & \text { lapacho') }\end{array}$


Otro tipo de compuestos frecuentes en ambas lenguas son los del tipo verbo atributivo unido a un sustantivo. En todos los casos del maká, el compuesto en su totalidad señala un atributo físico saliente de un animal, ejemplos (57) a (59), o de una planta, (60) y (61):

MK verbo atrib. + nombre $\rightarrow$ N

$\begin{array}{lll}\emptyset \text {-naya } & \text { t-enej } & \text { nayatenej } \\ \text { ser.saliente } & \text { POSs3-nariz } & \text { 'yacaré' ('su nariz es saliente') }\end{array}$

$\emptyset$-epk'etsaxji

te-jus

epk'etsaxjitejus

3-ser.ancho

POSS3-cara

'gualacate' ('su cara es ancha')

$\emptyset$-qi-ts

$t$-ekfi-i

qitstekfii

3-ser.grande-PL

POSS3-oreja-PL

'elefante' ('sus orejas son grandes')

$\emptyset$-fo'jitehe'm t-esej-ek

3-ser.blanca POSS3-hoja-CLlñ fo'jitehe'mt-esej-ek

'var. de planta' ('su hoja es blanca')

leek'ejit'op'om

'variedad de planta' ('su flor es azul')

En el caso del wichí, los compuestos atributivos que señalan al todo tienen la estructura sustantivo más verbo descriptivo que da como resultado un sustantivo:

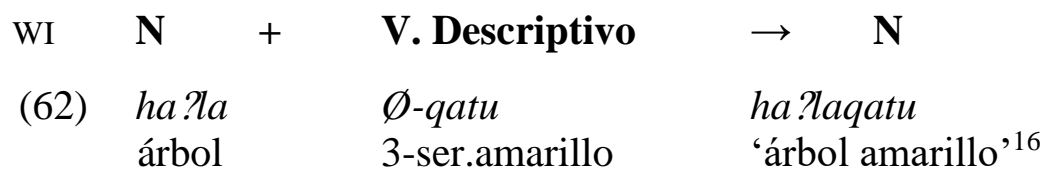

\subsubsection{Compuestos relacionales}

En las lenguas del mundo, los compuestos relacionales resultan de la concatenación de dos sustantivos, uno de los cuales -el núcleo- es un término de parentesco o de relación (padre, madre, hijo/a, sexo, parásito, habitante) y el otro es el término específico que

\footnotetext{
${ }^{16}$ Las hojas de este árbol se usan para teñir los hilos de cháguar. Desconocemos actualmente su nombre
} científico. 
designa el referente de dicha relación. Seguramente, por sus características semánticas específicas dichos términos son reclutados del vocabulario básico de la lengua para la clasificación de diversos conceptos. Es posible que, como resultado de un proceso más amplio de gramaticalización, estos sustantivos hayan perdido su significado original para derivar en términos de clase, es decir, morfemas clasificadores de claro origen léxico (Grinevald 2000 59-61), utilizados en procesos específicos de composición. Tanto en maká como en wichí encontramos compuestos relacionales con los lexemas tas 'su hijo' y teyte'(MK)/tele(WI) y 'su habitante'. En el caso del maká, los compuestos creados con el lexema tas 'su hijo' indican, en su primer significado, cría del lexema denotado por la base nominal, pero también extienden su significado y puede utilizarse como diminutivo o sufijo afectivo (véase Tacconi 2018):

\begin{tabular}{|c|c|c|c|}
\hline MK & $\mathbf{N}$ & $\rightarrow$ & $\mathbf{N}$ \\
\hline & kotes'eteyka' & $t$-as & kotes'eteyka'tas \\
\hline & ibra & POSs3-hijo & ‘cabrito' (lit. 'cabra su hijo') \\
\hline \multirow[t]{2}{*}{$(64)$} & tiptip & $t$-as & tiptiptas \\
\hline & caballo & POSs3-hijo & 'potrillo' (lit. 'caballo su hijo') \\
\hline \multirow[t]{2}{*}{$(65)$} & phof & $t-a s-i$ & phoftasi \\
\hline & pelota & POSS3-hijo-F & 'pelotita' (lit. 'pelota su hija') \\
\hline \multirow[t]{2}{*}{ (66) } & $y$-ewket & $t$-as & yewkettas \\
\hline & SS1-abuelo & POSs3-hijo & $\begin{array}{r}\text { 'mi abuelito' (lit. 'mi abuelo } \\
\text { su hijo') }\end{array}$ \\
\hline
\end{tabular}

Finalmente, también documentamos compuestos con el término tas que indican la variedad de una especie de ave:

(67) a. wonowotei

'tordo'

b. wonowotei-t-as

tordo-POs3-hijo

'tordo, boyero negro' (lit. 'tordo su hijo') (JB 69-70) 
En wichí, por su parte, $t$-as 'su hijo' crea lexemas compuestos para denominar a la cría del animal (ejemplos 68 y 69) y también con valor diminutivo (ejemplos 70 y 71):

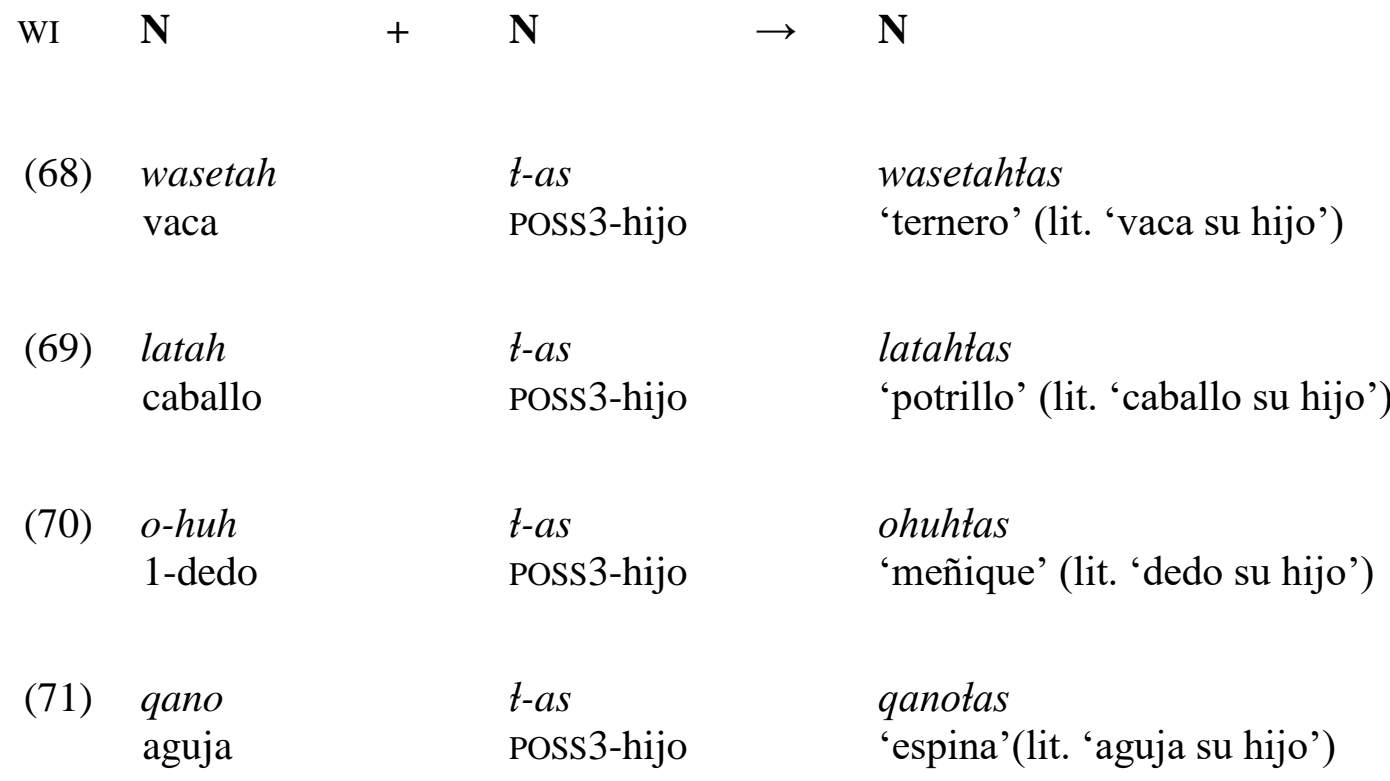

En ambas lenguas registramos entonces un camino común de gramaticalización que extiende el significado de 'hijo' para abarcar también el de diminutivo por extensión del significado de menor tamaño. Esta ruta de gramaticalización también es muy frecuente tipológicamente como establecen Heine y Kuteva (2002: 65).

En cuanto a los compuestos construidos con el término teyte' 'su habitante', estos también pueden considerarse relacionales. Dentro de este tipo de compuestos existen dos formas básicas. Los primeros resultan de la unión de dos sustantivos, el de la izquierda refiere a un lugar y el de la derecha a su 'habitante'. Es el caso de los compuestos de (72) y (73), que refieren a un animal que habita en el agua y a un insecto que habita en la arena, en ambos casos se sufija, además, la marca de género femenino:

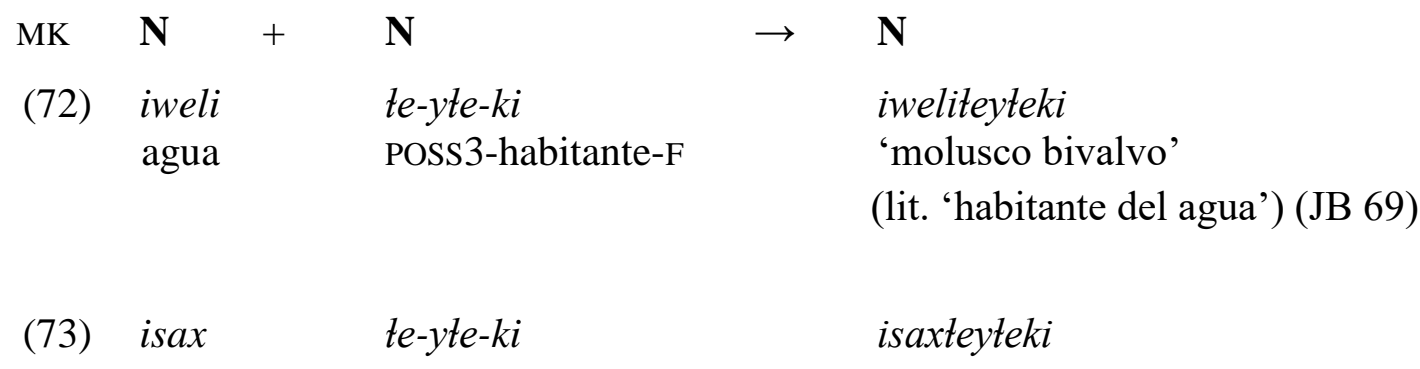


arena 'voss3-habitante-F de insecto'

(lit. 'habitante de la arena') (JB 73)

El segundo tipo de compuestos formados con el término teyte' se utilizan para especificar la variedad de una especie animal, por lo que están formados con tres lexemas: el que refiere a la especie, el que remite al lugar y el que designa al 'habitante'.

MK

(74) a. p'atax

'tortuga de tierra' (JB 70)

b. p'atax-iweli-te-yte-ki

tortuga.de.tierra-agua-POSS3-habitante-F

'tortuga de agua' (lit. 'tortuga habitante del agua') (JB 71)

En wichí también existe este tipo de compuestos formados con el cognado $t$-ele 'habitante':

WI

hohnat $+\quad$ t-ele

tierra

POSS3-habitante

hohnattele

'habitante de la tierra' 17

tahni

$+\quad$ t-ele 18

tahnitele

monte

POSs3-habitante

'habitante del monte'

(montaraz)

tewoq

río

\section{$+\quad$ t-ele}

POSs3-habitante

tewoqtele

'habitante del río'

(78)

honaci

$+\quad t$-ele-y

honaciteley

noche

POSS3-habitante-PL

'habitantes de la noche'

(79)

$$
\begin{aligned}
& \text { pule } \\
& \text { cielo }
\end{aligned}
$$

$+\quad t$-ele-y

puleteley

POSS3-habitante-PL

'habitantes del cielo/estrellas'

17 Entre los wichí "hohnatłele" hace referencia a esos seres que habitan el monte pero no son vistos, excepto por los chamanes. Sería una especie de "duende", también es llamado "espíritu maligno".

18 "Gente del monte" y "Gente del río" son dos de los gentilicios que se utiliza para clasificar los grupos dentro de la etnia wichí. 
Finalmente, otro término relacional que encontramos como un fenómeno marginal en maká y que se utiliza para indicar una variedad de insecto es el término 'amigo', como en el siguiente compuesto:

MK

$\begin{array}{lll}\text { (80) } \begin{array}{ll}\text { qametenax } \\ \text { tigre }\end{array} & \text { te-juwayka } & \text { qametenax-te-juwayka } \\ & \text { 'ass3-amigo } & \text { (lit. 'tigre su amigo') (JB 73) }\end{array}$

El fenómeno de los compuestos relacionales parece ser común también a otras lenguas del Chaco, como las guaycurúes. Por ejemplo, en toba se utilizan los términos late'e 'su madre' y lta 'a'su padre' para categorizar una variedad o especie en relación con otra que es conceptualizada como prototípica o más conocida. Así también, los términos lyale(k) 'hija/hijo' y lalaGat 'bicho/bichito' utilizados en compuestos nominales designan, respectivamente, la cría y aquella entidad 'que vuela', 'que se relaciona o depende de otra entidad’ o ‘de tamaño pequeño’ (cfr. Messineo y Cúneo 2007; Cúneo 2013).

\section{Un caso de gramaticalización: -wet/wet}

En maká, el morfema -wet se utiliza con valor locativo para formar sustantivos a partir de verbos. El lexema resultante indica 'lugar donde'. -wet tiene además un matiz de significado que expresa 'lugar general o abierto':

MK

(81) a. $y$-istax 3-estar.seco

'Está seco'

b. t-ista-wet

POSS3-estar.seco-LOC

'su isla' (lit. 'su lugar donde estar seco')

(82) a. n-iwhi-yu-ju'

3-acostarse-DES-CLIT

'Tiene ganas de acostarse' 
b. wit-iwhi-wet

POSIDF-acostarse ${ }^{19}$-LOC

'campamento' (lit. 'lugar donde acostarse')

a. hay-atsjatki

1-jugar al vóley

'Juego al vóley'

b. wit-atsjałki-wet

POSIDF-jugar.al.vóley-LOC

'cancha de vóley' (lit. 'lugar donde se juega al vóley’)

a.hey-tsukay

1-jugar.al.kas

'Juego al kas'

b.wi-tsuka-wet

POSIDF-jugar.al.kas-LOC

'cancha de kas' (lit. 'lugar donde se juega al kas')

En wichí, en cambio, el lexema wet posee el significado de 'lugar', es decir, indica el lugar donde se desarrolla una actividad sin hacer referencia a sus características físicas. Permite obtener sustantivos libres y posesivados al añadirse a otros lexemas nominales y verbales.

Cabe mencionar que una de las características que posee wet "lugar" es que puede funcionar como un sustantivo inalienable. Por ejemplo: o-wet 'mi lugar, mi casa', $a$-wet 'tu casa', la-wet 'su casa'.

WI

(83) tewoq

'río'

$\begin{array}{lll}\text { wiči } \\ \text { 'gente' }\end{array} \quad+\quad \begin{aligned} & \text { wet } \\ & \text { 'lugar' }\end{aligned}$

$\begin{array}{cc}o \text {-hus-eq } \\ 1 \text {-alma-NOM }\end{array} \quad+\quad \begin{gathered}\text { wet } \\ \text { 'lugar' }\end{gathered}$

tewoqwet $\left[\text { tewok }{ }^{w} e t\right]^{20}$

'playa'

o-huseqwet

'iglesia'[lit. 'casa del alma']

${ }^{19}$ Este verbo tiene como base el verbo de posición no vertical $-w$.

${ }^{20}$ En este ejemplo podemos observar que por cuestiones morfofonológicas, la uvular /q/ se convierte en velar labializada debido a la yuxtaposición con la semiconsonante /w/, así tenemos: tewok ${ }^{w}$ et. 
De igual modo, en chorote se observa su uso como un lexema pleno en la oración, acompañado por un prefijo posesivo:

(86) Juan $y$-i

Juan 3-estar

'Juan está en su casa'

$$
\text { ji-'wet-' } e \text { ' }
$$

POSS3-lugar-APL

Diversos autores han escrito sobre la dificultad de establecer límites claros entre los diferentes procesos de formación de palabras (derivación y composición) y la sintaxis (Matthews 1991; Bybee 1985; Booij 2005; entre otros). Esta problemática puede pensarse en términos de un continuum (Bybee 1985: 375). Un extremo está ocupado por la derivación canónica mediante afijos, luego se ubica la derivación mediante afijos que tienen su origen en lexemas independientes (por ejemplo, -mente en español o -wet en maká). En un lugar intermedio se hallan los compuestos propiamente dichos, es decir, la unión de dos lexemas indivisibles y con significado propio como unidad (como paraguas en español o wowotahatsjil 'cola de aguará guazú' en maká). En el otro extremo se encuentran las expresiones sintácticas, es decir aquellas frases que tienen un significado idiosincrático pero cuyos elementos constituyentes conservan cierta independencia ya que pueden ser flexionados internamente. Este extremo corresponde a la sintaxis (por ejemplo, meterse en un berenjenal que significa 'meterse en un lío'). El siguiente diagrama grafica este continuum:

\section{Diagrama 1: Continuum formación de palabras - sintaxis}

\section{Expresiones sintácticas Composición Derivación}

meterse en un berenjenal para-aguas suave-mente

Según el Diagrama 1, podemos decir que los compuestos se acercan a la derivación cuando uno de sus elementos está en un proceso de gramaticalización y se aproximan a la sintaxis cuando todavía no están establecidos como compuestos, es decir, cuando un afijo de flexión o un demostrativo puede, por ejemplo, insertarse entre los constituyentes del compuesto.

En lo que refiere al maká, hemos documentado algunos casos, en los cuales resulta difícil señalar el límite entre derivación, composición y frase sintáctica. 
En primer lugar, muchos sustantivos en esta lengua se forman mediante el sufijo LOCATIVO -wet que, adjuntado a verbos y sustantivos, indica el lugar donde se realiza la acción expresada por el verbo base (87) o relacionada semánticamente con el sustantivo (68).

(87) wit-lijtsii-wet

POSSINDF-cantar-lugar

'escenario' (lit. 'lugar para cantar')

(88) phofi-wet

pelota-lugar

'cancha de fútbol' (lit. 'lugar para pelota')

Tal como señalamos anteriormente, este sufijo no existe como lexema independiente en maká por lo que se lo considera derivativo (Tacconi y Abrach 2015).

La confrontación con los datos de otras lenguas de la familia mataguaya nos lleva a considerar que el sufijo derivativo en maká ha sido el resultado de la gramaticalización de un lexema independiente que, luego de pasar por el estadio de conformar un compuesto, derivó en afijo. El proceso de gramaticalización, en tanto fenómeno por el cual un lexema se vuelve más gramatical, puede observarse en estas tres lenguas que reflejan las diferentes fases. Una primera fase en que el lexema es independiente como en chorote o wichí (ji'wet'e' 'su casa', wet 'lugar, casa'); una segunda fase en que forma parte de un compuesto (chorote jlas(j)i'wet 'útero', wichí ma'wet' cama'); y, finalmente, su constitución como sufijo derivativo como en maká ( $t$-ista-wetPOS3-estar.seco-LOC 'isla' (lit. 'su lugar donde estar seco'); como se grafica en el siguiente diagrama:

\section{Diagrama 2: Gramaticalización lexema - sufijo}

$\begin{array}{crr}\underset{j i \text { 'wet' } e \text { ' 'su casa' }}{\text { lexema independiente }} & \text { compuesto } & \text { sufijo derivativo } \\ \text { (chorote) } & \text { ma'wet 'cama' } & \text { fis tawet 'isla' } \\ \text { (maká) }\end{array}$

\section{A modo de cierre}

En este trabajo abordamos diversos recursos de derivación y composición en dos lenguas de la familia mataguaya, wichí y maká. A pesar de que de acuerdo con el método 
comparativo léxico estas dos lenguas no tienen una relación tan estrecha, consideramos que los estudios comparativos entre ambas en otros niveles pueden arrojar luz sobre características de cada una de las lenguas así como sobre otras lenguas de la familia y del área.

Como se puede observar en la Tabla 1, existen varias coincidencias en cuanto a la morfología derivativa del maká y el wichí, tanto en la formación de léxico general como en la formación de léxico etnobiológico. En el caso de -tax parece haber un patrón de gramaticalización mediante el cual un morfema gramatical toma funciones cada vez más gramaticales, dado que en el wichí indica aumentativo y solo en algunos casos evaluativo; mientras que en el maká solo se encuentra su uso como evaluativo de flora y fauna.

Tabla 1

\begin{tabular}{|c|c|c|c|c|}
\hline \multirow[t]{2}{*}{$\begin{array}{l}\text { Valor semántico del } \\
\text { sufijo }\end{array}$} & \multicolumn{2}{|c|}{ Forma del sufijo } & \multicolumn{2}{|c|}{$\begin{array}{l}\text { Clase léxica de la } \\
\text { base y del lexema } \\
\text { final }\end{array}$} \\
\hline & maká & wichí & maká & Wichí \\
\hline $\begin{array}{c}\text { Instrumental/Agentiv } \\
\text { o }\end{array}$ & $-w o$ & $-w o$ & $\begin{array}{l}N \rightarrow N \\
V \rightarrow N\end{array}$ & $\begin{array}{l}N \rightarrow N \\
V \rightarrow N\end{array}$ \\
\hline Locativo/Recipiente & $\begin{array}{l}-w e t \\
-j i i\end{array}$ & $-h i$ & $\begin{array}{l}\mathrm{N} \rightarrow \mathrm{N} \\
\mathrm{V} \rightarrow \mathrm{N} \\
\end{array}$ & $\mathrm{N} \rightarrow \mathrm{N}$ \\
\hline Nombres abstractos & $\begin{array}{l}-(y) a x \\
-(y) e x\end{array}$ & $-(y) a h$ & $V \rightarrow N$ & $\mathrm{~V} \rightarrow \mathrm{N}$ \\
\hline $\begin{array}{c}\text { Evaluativo/Aumentati } \\
\text { vo }\end{array}$ & $\begin{array}{c}\text {-tax } \\
\text { para léxico } \\
\text { etnobiológico“ } \\
\text { variedad } \\
\text { anómala’ }\end{array}$ & $\begin{array}{l}-\operatorname{tah} \\
-\operatorname{tas}\end{array}$ & $\mathrm{N} \rightarrow \mathrm{N}$ & $\begin{array}{l}\mathrm{N} \rightarrow \mathrm{N} \\
\mathrm{V} \rightarrow \mathrm{N}\end{array}$ \\
\hline Leñosas & $-V k$ & $-u q$ & $\mathrm{~N} \rightarrow \mathrm{N}$ & $\mathrm{N} \rightarrow \mathrm{N}$ \\
\hline Fruto & $\begin{array}{l}-i l \\
-a x / \\
-a\end{array}$ & $-y$ & $\mathrm{~N} \rightarrow \mathrm{N}$ & $\mathrm{N} \rightarrow \mathrm{N}$ \\
\hline
\end{tabular}

En cuanto a la Tabla 2, podemos decir que también en la formación de compuestos hay coincidencias, sobre todo de orden semántico, entre ambas lenguas. Sin embargo, el wichí parece ser más productivo en cuanto a los diferentes tipos de lexemas finales (V o S) mientras que el maká solo cuenta con compuestos nominales. 
Tabla 2

\begin{tabular}{|c|c|c|}
\hline $\begin{array}{c}\text { Maká } \\
\text { Estructura }\end{array}$ & Tipo de compuesto & $\begin{array}{c}\text { Wichí } \\
\text { Estructura }\end{array}$ \\
\hline $\begin{array}{c}\mathrm{N}+\mathrm{N} \rightarrow \mathrm{N} \\
\text { Verbo des }+\mathrm{N}\end{array}$ & Parte/todo & $\begin{array}{c}\mathrm{N}+\mathrm{N} \rightarrow \mathrm{V} . \\
\text { descrip }\end{array}$ \\
$\rightarrow \mathrm{N}$ & $\mathrm{N}+\mathrm{V} \rightarrow \mathrm{N}$ \\
& Relacionales & \\
hijo & habitante & $\mathrm{N}+\mathrm{N}$ \\
\hline No existen & Locativos & Con - wet \\
\hline
\end{tabular}

El lexema/morfema -wet presenta un caso particular ya que nos permite observar el proceso de gramaticalización en dos lenguas diferentes. En el wichí es todavía un lexema independiente que puede formar parte de compuestos (como en chorote) mientras que en maká es un sufijo derivativo.

Los datos presentados en este trabajo permiten hipotetizar, aunque con cautela ya que sería necesaria una mayor cantidad de datos, que el maká parece estar más adelantado en el camino de gramaticalización que el wichí.

\section{Bibliografía}

Aikhenvald, Alexandra Y. Typological dimensions in word-formation.

LanguageTypology and SyntacticDescription. Grammatical Categories and the Lexicon. Vol. 3. Ed. Timothy Shopen. Cambridge UK: Cambridge University Press, 2007. 1-65.

Belaieff, Juan. "El vocabulario Maccá". Revista de la Sociedad Científica del Paraguay 3. 2 (1931): 53-67.

Belaieff, Juan. “El Maccá”. Revista de la Sociedad Científica del Paraguay 6.6 1940. (s.p). Booij, Geert. The Grammar of Words.Oxford: Oxford University Press, 2005. 
Braunstein, José. "El problema de la significación de la cultura material de los indios maká'.Tesis Universidad de Buenos Aires, Argentina, 1981.

Bybee, Joan. Morphology: A Study of the Relation Between Meaning and Form. Amsterdam: John Benjamins, 1985.

Censabella, Marisa. Las lenguas indígenas de la Argentina. Buenos Aires, Argentina: EUDEBA, 1999.

Claesson, Kenneth. "A phonological outline of mataco-noctenes". International Journal of American Linguistics, 60.2 (1994):1-38.

Cúneo, Paola. .Formación de palabras y clasificación nominal en el léxico etnobiológico en toba (guaycurú). Munich: Lincom Europa, 2013.

Cúneo, Paola. "Morfología evaluativa en toba". Edinburgh Handbook of Evaluative Morphology. Eds. Nicola Grandi y LíviaKörtvélyessy. Edinburgh: Edinburgh University Press, 2015. 625-633.

Fabre, Alain. "Los pueblos del Gran Chaco y sus lenguas, segunda parte: los mataguayo", Suplemento Antropológico 40.2 (2005): 313-435.

Gerzenstein, Ana. Lengua maká: Aspectos de la fonología. Buenos Aires, Argentina: UBA, FFYL, 1989.

Gerzenstein, Ana. Grados de transitividad en el verbo maká. Temas de lingüística aborigen Coord. A. Gerzenstein. Temas de lingüística aborigen. Buenos Aires, Argentina: UBA, FFYL, 1991. 39-56.

Gerzenstein, Ana. El maká. Estudio descriptivo. Buenos Aires, Argentina: Facultad de Filosofía y Letras, Universidad de Buenos Aires, 1995.

Gerzenstein, Ana. Diccionario etnolingüístico maká-español. Índice español-maká. Buenos Aires, Argentina: Universidad de Buenos Aires, Facultad de Filosofía y Letras, Instituto de Lingüística, 1999.

Gerzenstein, Ana. La construcción causativa en la lengua maká. Homenaje a Ofelia Kovacci Eds. E. N. de Arnoux y A. Di Tullio. Buenos Aires, Argentina: EUDEBA, 2001. 233-252.

Gerzenstein, Ana. Lengua indígena maká: el adjetivo, ¿una categoría autónoma o una subclase nominal o verbal? Actas del IX Congreso de la Sociedad Argentina de Lingüística, 2002. Argentina: Sociedad Argentina de Lingüística.

Gerzenstein, Ana. "Las consonantes laterales y las labializadas en lenguas mataguayas del chaco argentino-paraguayo". Buenos Aires, Argentina, 2002.

Grinevald, Colette. "A morphosyntactic typology of classifiers". Systems of Nominal Classification. Inglaterra: Ed. Gunter Senft.Cambridge, Cambridge University Press, 2000. 50-92.

Haspelmath, Martin. Undertanding Morphology. Oxford: Oxford University Press, 2002.

Heine, Bernd y Kuteva, Tania. World Lexicon of Grammaticalization. Cambridge: Cambridge UniversityPress, 2002.

Messineo, C. y Braunstein, J. "Variantes lingüísticas del mataco". Informe de Avance 1990/91. Ed. Centro del Chaco. Las Lomitas, Argentina: Centro del Hombre Antiguo Chaqueño, 1990.

Messineo, C. Lengua toba (guaycurú). Aspectos gramaticales y discursivos. Munich: Lincom Europa, 2003.

Messineo, C. y Cúneo, Paola. "Recursos lingüísticos para la clasificación de plantas y animales en dos lenguas indígenas del Chaco (toba y maká)". Proceedings of the III 
Conference on Indigenous Languages of Latin America, Center for Indigenous Languages of Latin America (CILLA), University of Texas at Austin, Austin, 25 al 27 de October 2007. U.S.A.: University of Texas at Austin. www.ailla.utexas.org/site/cilla3.

Messineo, C. "Modos de clasificación nominal en el dominio de la flora y de la fauna en maká (familia mataco-mataguaya)". UniverSOS 6 (2009): 119-138.

Messineo, C. y Cúneo, Paola. "Modos de clasificación nominal en toba (guaycurú) y maká (mataguaya): zoonimia y fitonimia". Léxico y categorización etnobiológica en grupos indígenas del Gran Chaco. Comps. Cristina Messineo, Gustavo Scarpa y Florencia Tola. Santa Rosa: UNLPam, 2010. 27-64.

Messineo, C. Aproximación tipológica a las lenguas indígenas del Gran Chaco. Rasgos compartidos entre toba (familia guaycurú) y maká (familia mataco-mataguayo). Indiana. Revista del Instituto Ibero-Americano de Berlín 28(2011): 183-225.

Messineo, C. "Indexación y sistemas de alineamiento en maká (mataco-mataguayo)". UniverSOS 12 (2015): 125-146.

Messineo, Carol, Harriet Javier y Harriet Klein. "Deixis y contacto en la región del Gran Chaco: los demostrativos en las lenguas guaycurúes y mataguayas". International Journal of Sociology of Language. (Volumen temático). New Indigenous Languages in Contact. Ed. A. Luykx. York: De Gruyter, 2016. 119-158.

Scarpa, Gustavo. "Fitonimia chorote: descripción, patrones nomenclaturales y comparación dialectal”. Actas del I Encuentro Internacional de Lenguas Indígenas. Santa Rosa, La Pampa, Argentina, 2006.

Schmidt, M. "Vocabulario de la lengua maká". Revista de la Sociedad Científica del Paraguay, 4. 2 (1937): 68-85.

Spinelli, Silvia. "La lengua wichí del Chaco salteño. Aspectos fonológicos y morfológicos”. Tesis doctoral Universidad Nacional de Córdoba, Argentina, 2015.

Suárez, María Eugenia. "Fitonimiawichí de especies arbóreas y arbustivas del Chaco Semiárido salteño". Léxico y categorización etnobiológica en grupos indígenas del Gran Chaco. Comps. Cristina Messineo, Gustavo F. Scarpa y Florencia Tola. Santa Rosa, Argentina: UNLPam, 2010.

Tacconi, Temis. "Algunas observaciones sobre el orden de constituyentes en maká (mataco-mataguaya) con especial referencia a la FN y a la FV". Lingüística Amerindia. Contribuciones y perspectivas. Eds. A. Fernández Garay, M. Censabella y M. Malvestitti. Buenos Aires, Argentina: Editorial de la Facultad de Filosofía y Letras, Universidad de Buenos Aires, 2013. 139-150.

Tacconi, Temis. "Towards a characterization of compounding in Maká Word Formation in South American Languages”. Eds. S. Danielsen, K. Hannss y F. Zúñiga. Amsterdam: John Benjamins, 2014.33-50.

Tacconi, Temis y Abrach, Luisina. "Resistencia étnica y creatividad lingüística entre los maká". Lenguas indígenas y lenguas minorizadas. Estudios sobre la diversidad (socio) lingüística de la Argentina y países limítrofes. Eds. Cristina Messineo y Ana Carolina Hecht. Buenos Aires, Argentina: EUDEBA, 2015.

Tacconi, Temis. "Formación de palabras en maká". Tesis doctoral Universidad de Buenos Aires, Argentina, 2015.

Tacconi, Temis. "La expresividad en la formación de palabras en maká (mataguaya)". UniverSOS. 13 (2016): 219-237. 
Tacconi, Temis. "Del léxico a la gramática: rutas de gramaticalización en maká". Káñina. 42. 2 (2018): 9-27.

Terraza, Jimena. Gramática del wichí: fonología y morfosintaxis. Universidad de Quebec, Montreal, 2009.

Tovar, Antonio. "El grupo mataco y su relación con otras lenguas de América del Sur", Congreso Internacional de Americanistas, Actas y Memorias 1964a. 439-452 México, D.F.: Instituto Nacional de Antropología e Historia.

Tovar, Antonio. "Relación entre las lenguas del grupo mataco", Homenaje a Fernando Márquez Miranda. Madrid: Universidad de Madrid y Sevilla, 1964b.

Vidal, Alejandra. "Noun Classification in Pilagá (Guaycuruan)". Journal Of Amazonian Languages, 1.1 (1997): 58-111.

Viegas Barros, Pedro. “¿Existe Una Relación Genética Entre Las Lenguas Mataguayas y Guaycurúes?” Hacia Una Nueva Carta Étnica Del Gran Chaco 5 (1993): 193-213.

Viñas Urquiza, María Teresa. Lengua Mataca. Buenos Aires, Argentina: Universidad de Buenos Aires, Facultad de Filosofía y Letras, 1974. 